\title{
A comparison of pathogenesis of Diabetes in China and the United States
}

\author{
Hui Wen ${ }^{1, *}$ \\ ${ }^{1}$ Department of Biostatistics \& Bioinformatics, Milken Institute School of Public Health, George Washington University, Washington, \\ DC, USA
}

\begin{abstract}
Diabetes Mellitus is a growing public health problem recent year. Diabetes has two main kinds: type 1 and type 2. Accumulating evidence suggests that genetic predisposition plays an important role in type 1 diabetes. This may be one reason that cause the difference between China and U.S. Within diabetes patients, more than $90 \%$ have type 2 diabetes. However, the prevalence of type 2 diabetes in China and United States of America is quite different, with $11.6 \%$ and $13 \%$ in two countries, respectively. Two countries with completely different cultures and histories have such slight differences in the prevalence of type 2 diabetes. Based on this fact, this paper will introduce the pathogenesis of diabetes and how it differs between the two countries.
\end{abstract}

\section{Introduction}

Diabetes is considered to be an epidemic disease that endangers the entire society. With population growth and population aging, the prevalence of diabetes is getting higher these years [1]. Diabetes is the sixth cause of death in the world, killing 1.6 million people in 2016 [2]. According to International Diabetes Federation, in 2019, about 463 million adults who aged 20 to 79 years old were living with diabetes and this number will rise to 700 million by 2045. Within this population, approximately $79 \%$ live in low- and middle- income countries. The IDF also states that more that $90 \%$ of diabetic patients are having type 2 diabetes [3]. The prevalence of diabetes in Chinese adult population is estimated to be $11.6 \%$ [4]. As of 2018, the prevalence of diabetes among aged 18 years or older in United States is $13 \%$ [5]. Past studies proved that the prevalence of diabetes varies significantly across regions [1]. However, there is little difference of the prevalence between China and United States. Therefore, this paper will discuss what causes this similar prevalence in two different countries.

There are three types of diabetes: type I, type 2, and gestational diabetes [5]. Type 2 diabetes accounts for around $90 \%$ of all diabetes cases because it is mainly affected by diet and lifestyle, whereas type 1 diabetes is not as common cases as type 2 diabetes and considered to be inherited [3]. Since type 2 diabetes is the most common form of diabetes, this paper will focus more on the causes of type 2 diabetes. The purpose of this article is to reveal the difference of prevalence between China and United States. In this review, we propose the past studies on diabetes mellitus in China and United States of America, while comparing the different factors that making these two countries developing the high rate of diabetes these years. Past studies have shown positive relationship between diabetes and obesity. Therefore, the factors of obesity will also be discussed in the article. Specifically, this report will focus on three primary topics: (1) the current state of diabetes in China and U.S.; (2) the role of genes in diabetes; (3) relationship between diabetes and obesity, divided by two parts: diet and lifestyle; (4) how alcohol causes and affects diabetes. Finally, important factors affecting diabetes in China and the United States will be summarized.

\section{Overview of Diabetes Mellitus}

\subsection{The Relationship of Insulin and Diabetes}

Diabetes is a chronic disease that fast-affecting world's population. International Diabetes Federation estimates currently there are 463 million people developed diabetes. They also prove within this population, half of them is undiagnosed. The number is still increasing in many countries [3]. For those people who are not aware of developing diabetes, they are at high risk of developing diabetes complications such as cardiovascular disease and stroke. According to International Diabetes Federation [3], around 700 million people will develop diabetes by 2045 . Diabetes has a high risk of premature death. It is estimated that one person dies every 8 seconds [3]. Within population affected by diabetes from all ages, including infants and elders, $72 \%$ are at a working age of $20-64$ [3]. It is popular in both male and female because of androgen deprivation in male and androgen excess in female [6].

\footnotetext{
* Corresponding author: wendy713@gwu.edu
} 


\subsection{The Types of Diabetes}

There are three types of diabetes: type I, type 2, and gestational diabetes [5]. Type 1 diabetes is an autoimmune disease. It is mainly caused by the destruction of $\beta$-cells in the pancreas that can produce insulin. Type 1 diabetes develops also because of genetic predisposition and environmental factors [7]. The characteristic of type 1 diabetes is that the body barely or do not produce insulin, so people have to inject insulin lifelong to maintain an ideal blood glucose level. Insulinpump therapy for type 1 diabetes patients is now widely used in order to control glycemic [8]. Type 1 diabetes can develop at any age, especially in children and adolescents [3]. Type 2 diabetes occurs because the body are not able to utilize insulin properly. Around $90 \%$ diabetes cases are type 2 diabetes. It is more common in adults. Most people with type 2 diabetes need to take oral drugs or insulin to keep their blood glucose level under control [5]. Besides, type 2 diabetes is also preventable. It is reported that the risk of type 2 diabetes can be reduced by $16 \%$ per kilogram weight loss [9]. The last kind of diabetes, Gestational diabetes (GDM), develops in pregnant women who have never had diabetes, which consists of high blood glucose during pregnancy. GDM will go away after pregnancy but the risk of type 2 diabetes in both woman and their baby will increase later in their life [3].

However, differ from the theoretical research, the incidence rate of type 2 diabetes is affected by numerous factors. According to the study by Lee, Brancati, \& Yeh [10], the risk of developing type 2 diabetes within Asian population is $20 \%-40 \%$ higher than the white population even though Asian population tend to have a lower BMI. One of the reasons for this phenomenon studied by Park et al. [11] is that Asian have more visceral adipose tissue (VAT) than the white, especially within female population.

In the following report, the impact factors of diabetes in China and the United States will be introduced from three perspectives: genes, obesity (including diet and lifestyle), and the role of alcohol.

\section{Gene}

It is reported the incidence of Type 1 diabetes is increasing 3\% per year [12]. In all age groups in China, the incidence of type 1 diabetes per 100,000 personyears is estimated to be 1.01[13]. In the United States, the prevalence of diabetes is $0.55 \%$, which represents approximately 1.3 million American adults [14]. Type 1 diabetes has high inherited susceptibility. HLA class II alleles account for $30 \%$ to $50 \%$ of the risk of inherited type 1 diabetes [15]. There is a significant relationship in risk of diabetes in familial relationship [16]. The patient's siblings' risk of developing T1D is 15 times higher than the general population's risk of developing T1D, especially the prevalence of monozygotic twins is much higher than that of dizygous twins [15]. Past studies suggest a significant difference of occurrence in type 1 diabetes between northern and southern hemisphere. Also, Asia has the lowest incidence and northern Europe has the highest incidence [17]. The change range in east and southeast Asia and Oceania is $2 \%$ and $60 \%$, respectively [1]. It shows that environmental factors play an important role in genes of developing diabetes. According to study by $\mathrm{Hu}$, diabetes is the product of the interaction of genetic and environmental factors. Most diagnosed diabetes susceptibility are related to impaired $\beta$-cells [18]. $\beta$-cells is used to produce and secrete insulin, so that hormone can regulate level of glucose in the blood. However, these cells are either destroyed by the immune system then lead to Type 1 diabetes, or produce insufficient insulin then lead to Type 2 diabetes. Also, KLF11 gene variants may also play a role in susceptibility to diabetes [19].

\section{Obesity}

The increasing prevalence of type 2 diabetes is closely related to accelerative incidence of obesity. Around $90 \%$ of type 2 diabetes is attributable to overweight or obesity [20]. Furthermore, the pathogenesis of obesity includes environmental factors, lifestyle, diet, as well as genetic factors. Past studies show a significant relationship between obesity and ethnic, which point out that genetic factor plays a role here [21]. Silventonen et al. suggest that genetic factors have a strong influence on BMI whether from childhood or adulthood. Therefore, interventions for obesity are urgent [22].

Obesity is now regarded as one of most serious risk factors of Type 2 Diabetes. It was traditionally considered as high-income country problem, but now it has a high prevalence in both low- and middle- income countries [2]. WHO also points that the common consequences of obesity include but not limited to diabetes, cardiovascular diseases, musculoskeletal disorders, and cancer. Evidence by Mokdad et al. [23] suggests that obesity is the most important factors for diabetes. It will also lead a metabolic abnormality of insulin resistance, so the ability of insulin will be decreased [24]. Therefore, past study concludes that the increase in BMI will lead an increase in the incidence of type 2 diabetes mellitus [25]. That is, the more the function of insulin will be affected by obesity, the higher the risk of people developing type 2 diabetes.

There is a significant difference in obesity between china and United States. China is the most populous country in the world and it is the largest developing country. The obesity rate in China is yearly increasing. Zhang et al. [26] stated that around 5.2\% people are obesity and $28.1 \%$ people are overweight in China, with the considerable variety between provinces. They also reported that people at age of $45-54$ has the highest prevalence of overweight and obesity in China. The prevalence of obesity in $2017-2018$ in America is $42.2 \%$, with the prevalence of obesity of $35 \%$ in male and $40.4 \%$ in female [5, 27]. In United States, approximately 280,000 people die from obesity related causes each year [28]. Past study notices that there is a significant linear trend in the prevalence of obesity 
among female population in America [27]. Most females in United States think there are several reasons such as genetic and environmental factors cause obesity, compare to male think it is because of diet habit and lifestyle [29]. As stated before, obesity is one of the potential factors to cause diabetes. However, pattern of the prevalence of diabetes and obesity between China and the US is quite different (Figure 1). We are trying to find out the reason behind this phenomenon.

\section{Prevalence of diabetes and obesity in China and U.S.}

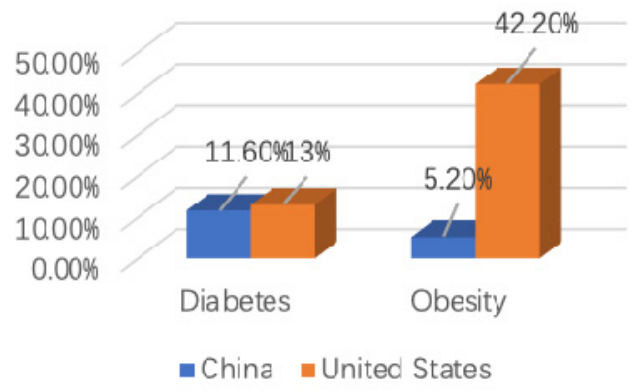

Fig. 1. Prevalence of diabetes and obesity in China and U.S.

\subsection{Diet}

The diet and structure of China and the United States are different. The Chinese diet is represented by cooking with large amount of oil, fat and salt. Past research has shown that saturated fats, sodium, and cholesterol content in Asian foods are significantly higher than western foods [30]. Additionally, starch, which is the common food in China, are able to resist degradation in earlier sections of the gastrointestinal tract to reach distal portions of the colon [31]. Western food such as McDonald's, Pizza Hut and other fast food always seem to have high calories. Long-chain fatty acids, which is the most abundant component of western foods, will adverse to obesity because it will enhance Th1 and Th17 cell differentiation more [32]. Gut microbiota also plays a significant role in metabolism of diet. Researchers proved that there is an association between diet-induced obesity and gut microbial ecology. They concluded, therefore, it leads an increased ability to promote host obesity [33]. Therefore, diet has a major impact on human health, and gut microbial plays an important role in mediating these effects.

Table 1. Food calories comparison between China and United States (per 100 gram)

\begin{tabular}{|c|c|c|c|}
\hline \multicolumn{2}{|c|}{ China } & \multicolumn{2}{c|}{ United States } \\
\hline Food Name & $\begin{array}{c}\text { Calories }(/ \\
100 \mathrm{~g})\end{array}$ & Food Name & $\begin{array}{c}\text { Calories }(/ 10 \\
0 \mathrm{~g})\end{array}$ \\
\hline Rice & 117 & $\begin{array}{c}\text { Cheese } \\
\text { Burger }\end{array}$ & 263 \\
\hline
\end{tabular}

\begin{tabular}{|c|c|c|c|}
\hline Noodles & 350 & $\begin{array}{c}\text { French } \\
\text { Fries }\end{array}$ & 325 \\
\hline $\begin{array}{c}\text { Kong Pao } \\
\text { Chicken }\end{array}$ & 135 & $\begin{array}{c}\text { Chicken } \\
\text { Nuggets }\end{array}$ & 282 \\
\hline $\begin{array}{c}\text { Stie-fried } \\
\text { Vegetable }\end{array}$ & 53 & $\begin{array}{c}\text { Pepperoni } \\
\text { Pizza }\end{array}$ & 276 \\
\hline
\end{tabular}

There is a transition from undernutrition to overnutrition during 1980s - 1990s after an economic and social change in China, with a large increase in egg, meat, and poultry consumption. Diet has predominantly changed in China. The level of energy from fat is presently high, especially in urban areas, increasing from $13.8 \%$ to $37.5 \%[34,35]$. People tend to consume more high-fat diet, animal foods, and edible oil instead of traditional foods like rice and wheat products [36]. Du et al. also points out that flour and rice are no longer as valuable as before [36]. They further predict that the consumption of these two staple goods will decrease more with the higher future income. Also, refined grains, which has known can rapidly raise blood glucose levels, is much more popular than whole grains. With such high-energy density, high-fat and low-fiber diets, people have higher risk to get type 2 diabetes. Moreover, higher income will bring an increase consumption on animal foods, particularly in low-income family. Animal foods were expensive for most Chinese people before 1988 [36]. However, with the high speed of economic and social development, animal foods are no luxury foods but a normal daily proportion of their daily meal. Du et al. also pointed a significant increase of incidence of overweight and obesity in low-income family from $6.3 \%$ to $10.9 \%$ in 10 years [36]. The same standard rate in high income family increase from $10.7 \%$ in 1989 to $19.6 \%$ in 1997 . Therefore, they also concluded there is a positive linear relationship between income and prevalence of overweight and obesity. In addition, China has an extremely unbalanced economic throughout the country, with highly developed cities in southeast coastal areas and lower developing cities in mainland. Therefore, because of both economic development and educational level, people in northern China are tend to consume more animal foods and high starch foods. This is the reason why the prevalence of overweight and obesity in northeast and northwest is higher than it is in southeast [26].

The lack of healthy food is one of main reason why the prevalence of obesity is high in United States of America. In his investigation into the relationship between obesity and poverty, Levine shows that Americans are the most prone to obesity and developing diabetes if they live in the most poverty-dense counties [37]. He pointed out the reason why is because it is hard for people in poverty country to get fresh food, and the healthy foods are in short supply [37]. World Health Organization have proved that there is a positive linear relationship between the fast-food consumption and prevalence of obesity [38]. In United States, some fast foods like burger or pizza are much cheaper than vegetables. This will cause most poverty people tend to consume more fast foods other than healthy foods. A 
study by Harvard Medical School suggests that added sugar in soft beverages make up around $10 \%$ of the daily calories Americans take per day. Researchers at Harvard Medical Schoolalso proved that the higher intake of sweetened beverages will cause the obesity [39]. In addition, according to The U.S. Department of Agriculture [40], the average calories Americans take was $20 \%$ in 2000 than it was in 1983 , because the consumption of meat increased from 138 per person per year to 195 per person per year. Increased daily calories and consumption of fats cause an increase prevalence of overweight and obesity in United States.

\subsection{Lifestyle: physical activity}

Obesity can also be caused by sedentary lifestyle. Lacking of exercise is associated with a series of adverse health consequences, the most important one is obesity. The regular exercise plays an important role in daily life. Past studies suggest there is a positive correlation between protein consumption and microbial diversity. In their study, athletes have a significantly higher diversity of gut microbiota compare to the control group [41]. Microbial diversity is important to promote stability and performance [41]. According to Sun and Zhu's research [42], intestinal bacteria can increase the catabolism of muscle fat, thereby resisting diet-induced obesity. However, the frequency of exercise decreased significantly in both China and USA.

The reason why the decrease of exercise among Chinese people increases these years may cause by urbanization, development of transportation and society. With the increase of manufacturing and service industries, traditional agriculture that requires a lot of manual labor is gradually decreasing. Bell, Ge, \& Popkin [43] reported on a new study for association between work load level and obesity and conclude that light work-related physical activity is the most important predictor of weight gain. Also, due to advances social transportation, physical activities in daily life have been greatly reduced these years. The weekly physical activity of Chinese adults fell by 32\% from 1991 to 2006 [44]. As a consequence, the prevalence of obesity increases these years. Bell, Ge, \& Popkin [45] did another study on association between obesity and household ownership of motorized transportation in both male and female in China. They concluded that the odds of being obese are $80 \%$ higher among those who own a vehicle, compare with people who do not have a vehicle.

Furthermore, urbanization may be another reason for people having less physical exercise in China. Popkin suggests that the prevalence of obesity of urban areas in China is $23.1 \%$, compare to $10.2 \%$ in rural areas. He also pointed out that rural residents tend to have much more physical activities than urban residents [46]. The prevalence of diabetes is $6 \%$ higher in male and $4 \%$ higher in female in more-urbanized areas than lessurbanizes areas [47]. In China, low proportion of people exercises after work. It is even much lower in cities. Muntner and his colleague [23] found that less than 25\% of Chinese adults (35-74 years old) can do a moderate a 30-minute exercise every day, while less than $7.9 \%$ of the urban population do a regular exercise.

The United States is also facing a serious problem of physical inactivity. Long-time sedentary time, poverty, education, and even season can be the reason why American people have a low rate of physical exercise. In Tudor-Locke et al.'s study [48], only 3.2\% of American adults achieve the public health guidelines of physical activities. They also pointed out that male is more physically active, and have less sedentary time than female. This also explains why the obesity rate among female is higher than male in U.S. Past studies also prove that high level of television viewing has a significantly positive impact on obesity $[49,50]$. It is because the longer duration of viewing television, the shorter time people have to do some physical exercises. In addition, lower education family may be a factor causing people and their children to have longer sedentary time compare to a well-educated family [51]. Furthermore, poverty may be another reason why people in the U.S. is in lack of physical activity. Violence and lack of sidewalks in poverty county may hamper residents to have outdoor physical activities [37]. Also, it is been reported that season has a significant impact on physical activity with the highest percentage of people exercise in summer and low percentage in winter in U.S. [52].

\section{Alcohol}

As one of the most popular drink all over the world, there is a causal relationship between alcohol intake and risk of diabetes [53]. It will also bring huge social and economic burden and health problems. Harmful use of alcohol causes 3 million death every year, which is 5.3\% of all death [2]. Consuming more alcohol will lead a deterioration in insulin sensitivity. In addition, long-term or excessive drinking may reduce insulin resistance, which is one of the main pathophysiological mechanisms underlying diabetes. Researchers also noticed that compare to female, male tends to have a higher significance in alcohol consumption and insulin resistance as well as other diabetes-related traits [54]. Zhang et al. [55] suggest that the risk of developing type 2 diabetes among alcohol drinker is $4.2 \%$ higher than non-drinkers. Daily intake of more than $30 \mathrm{~g}$ alcohol will definitely increase the incidence of diabetes. However, it has also proved that consumption of alcohol around $22 \mathrm{~g}$ a day will have the most significant protective effect on male who developed diabetes and $24 \mathrm{~g}$ a day for female $[53,56]$. Therefore, people should have an adequate control of taking alcohol.

\section{Conclusion}

In summary, this paper discussed the pathogenesis of Diabetes between China and the United States, which is not only the difference in diet between the two countries, but also people's physical inactivity due to economic and cultural reasons. Moreover, the fact is that the obesity rate in the United States far exceeds it is in China, which 
means that Americans may more likely to develop type 2 diabetes. However, the difference between the two countries in the prevalence of type 2 diabetes is only $1.4 \%$. This may be because the previous studies are too general, other factors may also lead to this result. Furthermore, type 1 diabetes has caused huge differences in geographic location and ethnicity, that is, Asia has the fewest people developed type 1 diabetes, while the prevalence rate is the highest in Northern Europe. However, there are few researches focus on studying type 1 diabetes in China and the United States. This is what needs to continue to study and explore in the future.

\section{References}

1. Danaei, G., Finucane, M. M., Lu, Y., Singh, G. M., Cowan, M. J., Paciorek, C. J., . . Ezzati, M. (2011). National, regional, and global trends in fasting plasma glucose and diabetes prevalence since 1980: systematic analysis of health examination surveys and epidemiological studies with 370 country-years and 2.7 million participants. The Lancet, 378(9785), 31-40. doi:10.1016/s0140-6736(11)60679-x

2. The World Health Organization. (2020, December 3). WHO. https://www.who.int/

3. International Diabetes Federation. (2019). IDF Diabetes Atlas Ninth edition 2019. https://diabetesatlas.org/upload/resources/material/2 0200302 133351_IDFATLAS9e-final-web.pdf

4. Xu, Y., Wang, L., He, J., Bi, Y., Li, M., Wang, T., . . China Noncommunicable Disease Surveillance, G. (2013). Prevalence and control of diabetes in Chinese adults. JAMA, 310(9), 948-959. doi:10.1001/jama.2013.168118

5. Centers for Disease Control and Prevention. (2020, December 4). CDC. https://www.cdc.gov/

6. Navarro, G., Allard, C., Xu, W., \& Mauvais-Jarvis, F. (2015). The role of androgens in metabolism, obesity, and diabetes in males and females. Obesity, 23(4), 713-719.

doi:http://dx.doi.org.proxygw.wrlc.org/10.1002/oby. 21033

7. Bluestone, J. A., Herold, K., \& Eisenbarth, G. (2010). Genetics, pathogenesis and clinical interventions in type 1 diabetes. Nature, 464(7293), 1293-1300. doi:10.1038/nature08933

8. Pickup, J. C. (2012). Insulin-Pump Therapy for Type 1 Diabetes Mellitus. New England Journal of Medicine, 366(17), 1616-1624. doi:10.1056/NEJMct1113948

9. Hamman, R. F., Wing, R. R., Edelstein, S. L., Lachin, J. M., Bray, G. A., Delahanty, L., . . . Wylie-Rosett, J. (2006). Effect of weight loss with lifestyle intervention on risk of diabetes. Diabetes Care, 29(9), 2102-2107. doi:10.2337/dc06-0560

10. Lee, J. W., Brancati, F. L., \& Yeh, H. C. (2011). Trends in the prevalence of type 2 diabetes in Asians versus whites: results from the United States National Health Interview Survey, 1997-2008.
Diabetes Care, 34(2), 353-357. doi:10.2337/dc100746

11. Park, Yong-Woo, et al. "Larger Amounts of Visceral Adipose Tissue in Asian Americans." Obesity Research, vol. 9, no. 7, 2001, pp. 381-387., doi:10.1038/oby.2001.49.

12. Onkamo, P., Väänänen, S., Karvonen, M., \& Tuomilehto, J. (1999). Worldwide increase in incidence of Type I diabetes-the analysis of the data on published incidence trends. Diabetologia, 42(12), 1395-1403.

13. Weng, J., Zhou, Z., Guo, L., Zhu, D., Ji, L., Luo, X., ... Group, T. D. C. S. (2018). Incidence of type 1 diabetes in China, 2010-13: population based study. BMJ, 360, j5295. doi:10.1136/bmj.j5295

14. Bullard KM, Cowie CC, Lessem SE, et al. Prevalence of Diagnosed Diabetes in Adults by Diabetes Type — United States, 2016. MMWR Morb Mortal Wkly Rep 2018;67:359-361. DOI: http://dx.doi.org/10.15585/mmwr.mm6712a2externa 1 icon

15. Steck, A. K., \& Rewers, M. J. (2011). Genetics of type 1 diabetes. Clin Chem, 57(2), 176-185. doi:10.1373/clinchem.2010.148221

16. Atkinson, M. A., \& Maclaren, N. K. (1994). The pathogenesis of insulin-dependent diabetes mellitus. New England Journal of Medicine, 331(21), 14281436.

17. Karvonen, M., Tuomilehto, J., Libman, I., \& LaPorte, R. (1993). A review of the recent epidemiological data on the worldwide incidence of type 1 (insulin-dependent) diabetes mellitus. Diabetologia, 36(10), 883-892.

18. Hu, F. B. "Globalization of Diabetes: The Role of Diet, Lifestyle, and Genes." Diabetes Care, vol. 34, no. 6, 2011, pp. 1249-1257., doi:10.2337/dc11-0442.

19. Neve, B., Fernandez-Zapico, M. E., AshkenaziKatalan, V., Dina, C., Hamid, Y. H., Joly, E., . . . Froguel, P. (2005). Role of transcription factor KLF11 and its diabetes-associated gene variants in pancreatic beta cell function. Proc Natl Acad Sci U S A, 102(13), 4807-4812. doi:10.1073/pnas.0409177102

20. Hossain, P., Kawar, B., \& El Nahas, M. (2007). Obesity and diabetes in the developing world-a growing challenge. New England Journal of Medicine, 356(3), 213-215.

21. Knowler, W. C., Pettitt, D. J., Saad, M. F., \& Bennett, P. H. (1990). DIABETES-MELLITUS IN THE PIMA-INDIANS - INCIDENCE, RISKFACTORS AND PATHOGENESIS. DiabetesMetabolism Reviews, 6(1), 1-27. doi:10.1002/dmr.5610060101

22. Silventoinen, K., Rokholm, B., Kaprio, J., \& Sorensen, T. I. (2010). The genetic and environmental influences on childhood obesity: a systematic review of twin and adoption studies. Int $\mathrm{J}$ 
Obes (Lond), 34(1), 29-40.

doi:10.1038/ijo.2009.177

23. Muntner, P., Gu, D., Wildman, R. P., Chen, J., Qan, W., Whelton, P. K., \& He, J. (2005). Prevalence of physical activity among Chinese adults: results from the International Collaborative Study of Cardiovascular Disease in Asia. American journal of public health, 95(9), 1631-1636.

24. Yamaguchi, S., \& Yoshino, J. (2017). Adipose tissue $\mathrm{NAD}(+)$ biology in obesity and insulin resistance: From mechanism to therapy. Bioessays, 39(5). doi:10.1002/bies.201600227

25. Ford, E. S., et al. "Weight Change and Diabetes Incidence: Findings from a National Cohort of US Adults." American Journal of Epidemiology, vol. 146, no. 3, 1997, pp. 214-222., doi:10.1093/oxfordjournals.aje.a009256.

26. Zhang, L., Wang, Z., Wang, X., Chen, Z., Shao, L., Tian, Y., . . . China Hypertension Survey, i. (2020). Prevalence of overweight and obesity in China: Results from a cross-sectional study of 441 thousand adults, 2012-2015. Obes Res Clin Pract, 14(2), 119126. doi:10.1016/j.orcp.2020.02.005

27. Flegal, K. M., Kruszon-Moran, D., Carroll, M. D., Fryar, C. D., \& Ogden, C. L.(2016). Trends in Obesity Among Adults in the United States, 2005 to 2014. JAMA, 315(21), 2284-2291. doi:10.1001/jama.2016.6458

28. Allison, David B. "Annual Deaths Attributable to Obesity in the United States." Jama, vol. 282, no. 16, 1999, p. 1530., doi:10.1001/jama.282.16.1530.

29. Rosenthal, R. J., Morton, J., Brethauer, S., Mattar, S., De Maria, E., Benz, J. K., . . . Sterrett, D. (2017). Obesity in America. Surg Obes Relat Dis, 13(10), 1643-1650. doi:10.1016/j.soard.2017.08.002

30. Henry, C. J., Kaur, B., \& Quek, R. Y. C. (2020). Are Asian foods as "fattening" as western-styled fast foods? European journal of clinical nutrition, 74(2), 348-350.

31. Portune, K. J., Benítez-Páez, A., Del Pulgar, E. M. G., Cerrudo, V., \& Sanz, Y. (2017). Gut microbiota, diet, and obesity-related disorders-The good, the bad, and the future challenges. Molecular nutrition \& food research, 61(1), 1600252.

32. Haghikia, A., Jörg, S., Duscha, A., Berg, J., Manzel, A., Waschbisch, A., ... Wilck, N. (2015). Dietary fatty acids directly impact central nervous system autoimmunity via the small intestine. Immunity, 43(4), 817-829.

33. Turnbaugh, P. J., Bäckhed, F., Fulton, L., \& Gordon, J. I. (2008). Diet-induced obesity is linked to marked but reversible alterations in the mouse distal gut microbiome. Cell host \& microbe, 3(4), 213-223.

34. Popkin, B. M. (1999). Urbanization, Lifestyle Changes and the Nutrition Transition. World Development, 27(11), 1905-1916. https://doi.org/10.1016/s0305-750x(99)00094-7
35. Du, S., Mroz, T. A., Zhai, F., \& Popkin, B. M. (2004). Rapid income growth adversely affects diet quality in China--particularly for the poor! Soc Sci Med, 59(7), 1505-1515. doi:10.1016/j.socscimed.2004.01.021

36. Du, S., Lu, B., Zhai, F., \& Popkin, B. M. (2002). A new stage of the nutrition transition in China. Public Health Nutr, 5(1A), 169-174. doi:10.1079/PHN2001290

37. Levine, James A. "Poverty and Obesity in the U.S.: FIG. 1.” Diabetes, vol. 60, no. 11, 2011, pp. 26672668., doi:10.2337/db11-1118.

38. De Vogli, R., Kouvonen, A., \& Gimeno, D. (2014). The influence of market deregulation on fast food consumption and body mass index: a cross-national time series analysis. Bull World Health Organ, 92(2), 99-107, 107A. doi:10.2471/BLT.13.120287

39. Bermudez, O. I., \& Gao, X. (2010). Greater consumption of sweetened beverages and added sugars is associated with obesity among US young adults. Ann Nutr Metab, 57(3-4), 211-218. doi: $10.1159 / 000321542$

40. USDA ERS - Food Availability and Consumption. (2020). United States Department of Agriculture. https://www.ers.usda.gov/data-products/ag-andfood-statistics-charting-the-essentials/foodavailability-and-consumption/

41. Clarke, S. F., Murphy, E. F., O'Sullivan, O., Lucey, A. J., Humphreys, M., Hogan, A., . . Cotter, P. D. (2014). Exercise and associated dietary extremes impact on gut microbial diversity. Gut, 63(12), 1913-1920. doi:10.1136/gutjnl-2013-306541

42. Sun, X., \& Zhu, M. J. (2017). AMP-activated protein kinase: a therapeutic target in intestinal diseases. Open Biol, 7(8). doi:10.1098/rsob.170104

43. Bell, Ac, et al. "Weight Gain and Its Predictors in Chinese Adults." International Journal of Obesity, vol. 25, no. 7, 2001, pp. 1079-1086., doi:10.1038/sj.ijo.0801651.

44. Ng, S. W., Norton, E. C., \& Popkin, B. M. (2009). Why have physical activity levels declined among Chinese adults? Findings from the 1991-2006 China Health and Nutrition Surveys. Social science \& medicine, 68(7), 1305-1314.

45. Bell, A. Colin, et al. "The Road to Obesity or the Path to Prevention: Motorized Transportation and Obesity in China." Obesity Research, vol. 10, no. 4, 2002, pp. 277-283., doi:10.1038/oby.2002.38.

46. Popkin, Barry M., et al. "Trends in Diet, Nutritional Status, and Diet-Related Noncommunicable Diseases in China and India: The Economic Costs of the Nutrition Transition." Nutrition Reviews, vol. 59, no. 12, 2009, pp. 379-390., doi:10.1111/j.17534887.2001.tb06967.x.

47. Attard, S. M., Herring, A. H., Mayer-Davis, E. J., Popkin, B. M., Meigs, J. B., \& Gordon-Larsen, P. (2012). Multilevel examination of diabetes in modernising China: what elements of urbanisation 
are most associated with diabetes? Diabetologia, 55(12), 3182-3192. doi:10.1007/s00125-012-269781

48. Tudor-Locke, C., Brashear, M. M., Johnson, W. D., \& Katzmarzyk, P. T. (2010). Accelerometer profiles of physical activity and inactivity in normal weight, overweight, and obese U.S. men and women. Int J Behav Nutr Phys Act, 7, 60. doi:10.1186/14795868-7-60

49. Hu, J., Ding, N., Yang, L., Ma, Y., Gao, M., \& Wen, D. (2019). Association between television viewing and early childhood overweight and obesity: a pairmatched case-control study in China. BMC Pediatr, 19(1), 184. doi:10.1186/s12887-019-1557-9

50. Lakerveld, J., Dunstan, D., Bot, S., Salmon, J., Dekker, J., Nijpels, G., \& Owen, N. (2011). Abdominal obesity, TV-viewing time and prospective declines in physical activity. Prev Med, 53(4-5), 299-302. doi:10.1016/j.ypmed.2011.07.012

51. Sherar, L. B., Griffin, T. P., Ekelund, U., Cooper, A. R., Esliger, D. W., van Sluijs, E. M., . . Page, A. S. (2016). Association between maternal education and objectively measured physical activity and sedentary time in adolescents. J Epidemiol Community Health, 70(6), 541-548. doi:10.1136/jech-2015-205763

52. Merrill, Ray M., et al. "Climate Conditions and Physical Activity in the United States." American Journal of Health Behavior, vol. 29, no. 4, 2005, pp. 371-381., doi:10.5993/ajhb.29.4.9.

53. Lee, D. Y., Yoo, M. G., Kim, H. J., Jang, H. B., Kim, J. H., Lee, H. J., \& Park, S. I. (2017). Association between alcohol consumption pattern and the incidence risk of type 2 diabetes in Korean men: A 12-years follow-up study. Sci Rep, 7(1), 7322. doi:10.1038/s41598-017-07549-2

54. Peng, M., Zhang, J., Zeng, T., Hu, X., Min, J., Tian, S., . . . Chen, L. (2019). Alcohol consumption and diabetes risk in a Chinese population: a Mendelian randomization analysis. Addiction, 114(3), 436-449. doi:10.1111/add.14475

55. Zhang, S., Liu, Y., Wang, G., Xiao, X., Gang, X., Li, F., . . . Wang, G. (2016). The Relationship between Alcohol Consumption and Incidence of Glycometabolic Abnormality in Middle-Aged and Elderly Chinese Men. Int J Endocrinol, 2016, 1983702. doi:10.1155/2016/1983702

56. Baliunas, D. O., Taylor, B. J., Irving, H., Roerecke, M., Patra, J., Mohapatra, S., \& Rehm, J. (2009). Alcohol as a risk factor for type 2 diabetes: A systematic review and meta-analysis. Diabetes Care, 32(11), 2123-2132. doi:10.2337/dc09-0227 